\title{
Consumption of fertilizers in districts of Slovakia in the period 2006-2015
}

\author{
CYRIL SIMAN - YVETTA VELÍSKOVÁ \\ Institute of Hydrology Slovak Academy of Sciences, \\ Bratislava, Slovak Republic \\ siman@uh.savba.sk
}

\begin{abstract}
Summary
Consumption of fertilizers in districts of Slovakia in the period 2006-2015

Water quality in the surface streams is influenced by several factors. One of important information which can help us to solve problems with quality of water in water body is a distribution of point and non-point pollution sources in a river basin and also amount of pollutants released from them to surface streams. An example of a point source of pollution is the outlet from wastewater treatment plants (industry, urban areas, farms, etc.). On the other hand the most significant non-point source of pollution is considered the application of fertilizers in agriculture.

In this paper we have evaluated consumption of organic and industrial fertilizers in Slovakia in the period 2006-2015. Total (in tonnes) and average (in $\mathrm{kg} \mathrm{ha}{ }^{-1}$ ) consumption of industrial and organic fertilizers was analyzed. In monitored period, the amount of applied organic fertilizers was much higher than the amount of applied industrial fertilizers and in addition a significant part of total fertilizers consumption had nitrogenous fertilizers in a group of industrial fertilizers. In a group of industrial fertilizers during the period 2006-2015 we observed just moderately increasing in their consumption, while in the period 2010-2015 the average amount of applied industrial fertilizers per hectare of agricultural land increased by about $20 \mathrm{~kg} \mathrm{ha}^{-1}$. On the other hand, in a group of organic fertilizers we observed a decreasing in consumption of fertilizers
\end{abstract}

Keywords: agriculture, non-point source of pollution, industrial and organic fertilizers, surface streams, water quality

\section{Introduction}

Research of water quality degradation caused by point and nonpoint source pollution plays an important role in protecting the environment sustainability (Lam et al., 2011; Kováčová, 2017). The Water Framework Directive (Directive, 2000) that rules the current European water policy defines water quality as the level of deviation from the type-specific 'reference conditions'. Water quality in surface streams is expressed by physical, chemical and biological indicators (Říha et al., 2002) and is affected by a combination of natural and anthropogenic factors, the 
relative influences of which change their temporal and spatial scale (Meybeck et al., 1989; Mouri et al., 2011). One kind of pollution problem is caused by changes in the composition of land use within a catchment as human activities increase (Gikas et al., 2006; Amiri and Nakane, 2009; Boskidis et al., 2011).

Sources of pollution are divided into point and non-point ones (Fischer et al., 1979) and their occurrence is more frequent in areas where industry, settlement (urbanized areas) and intensive agricultural activity are located. Point pollution of surface streams comes mainly from inadequately cleaned water from municipal and industrial sewage. The main non-point sources of pollution are flush waters from agriculture areas with application of industrial and organic fertilizers. Agriculture has been identified as the major contributor of non-point (diffuse) source pollution of water resources (Humenik et al., 1987; Duda, 1993; Behrendt et al., 1999; Lam et al., 2010). Some other studies have found that pollutants such as fertilizers, pesticides, and sediment, resulting from various agricultural practices, lead to the degradation of surface and groundwater (Donoso et al., 1999; Zalidis et al., 2002). Point and nonpoint (diffuse) source pollution becomes a serious problem causing the damage of water quality in many European countries (Lam et al., 2011). These factors can be classified as anthropogenically dependent influences affecting water quality in surface streams.

In this paper the summary of distribution and amount of the potential non-point source of surface streams pollution in Slovakia territory is presented. In this relation the application of organic and industrial fertilizers on agricultural land is considered in majority.

\section{Data and methods}

The data of the consumption of fertilizers on agricultural land for the individual districts of Slovakia during the period 2006-2015 was provided by the Central Agricultural Control and Testing Institute in Bratislava. Evaluation of fertilizer consumption was done by calculation of the total (in tonnes) and average (in kg ha-1 year-1) level of fertilization during the period 2006-2015. The input data in the case of total fertilizers consumption as a summary of fertilizer application amount during the evaluated period was in tonnes per hectare of agriculture land $\left(t \mathrm{ha}^{-1}\right)$, on the other side, in the case of average fertilizers consumption, which is represented by average value per one year in monitored period, data was

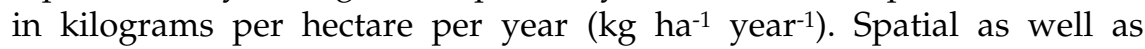
temporal distribution of fertilizers consumption are presented by maps (Figure 1, 3, 4, 5 and 7) and graphs $(2,6,8,9,10,11,12,13)$. 


\section{Results}

We have evaluated consumption of organic and industrial fertilizers in all districts of Slovakia during the period 2006-2015. Data about fertilizers consumption in $\mathrm{kg} \mathrm{ha}^{-1}$ and tonnes was provided by Central Control and Testing Institute of Agriculture in Slovakia.

Total (in tonnes) and average annual (in kilograms per hectare per year) consumption of industrial and organic fertilizers was analyzed. The amount of industrial and organic fertilizers was applied on monitored agricultural land, so for this reason only size of this area was taken into account. The value of monitored agricultural area was different in each year. From Figure 2 it is evident a slightly increasing trend in monitored value of agricultural land area during the period 2006-2015. For this reason there was calculated average value of this parameter for statistical processing of the fertilizers consumption in particular districts of Slovakia in evaluated period (Figure 1). However, the highest monitored area of agricultural land was in the south part of Slovakia primarily (Figure 1).

Figure 1. Average annual monitored area of agricultural land in the districts of Slovakia in the period 2006-2015

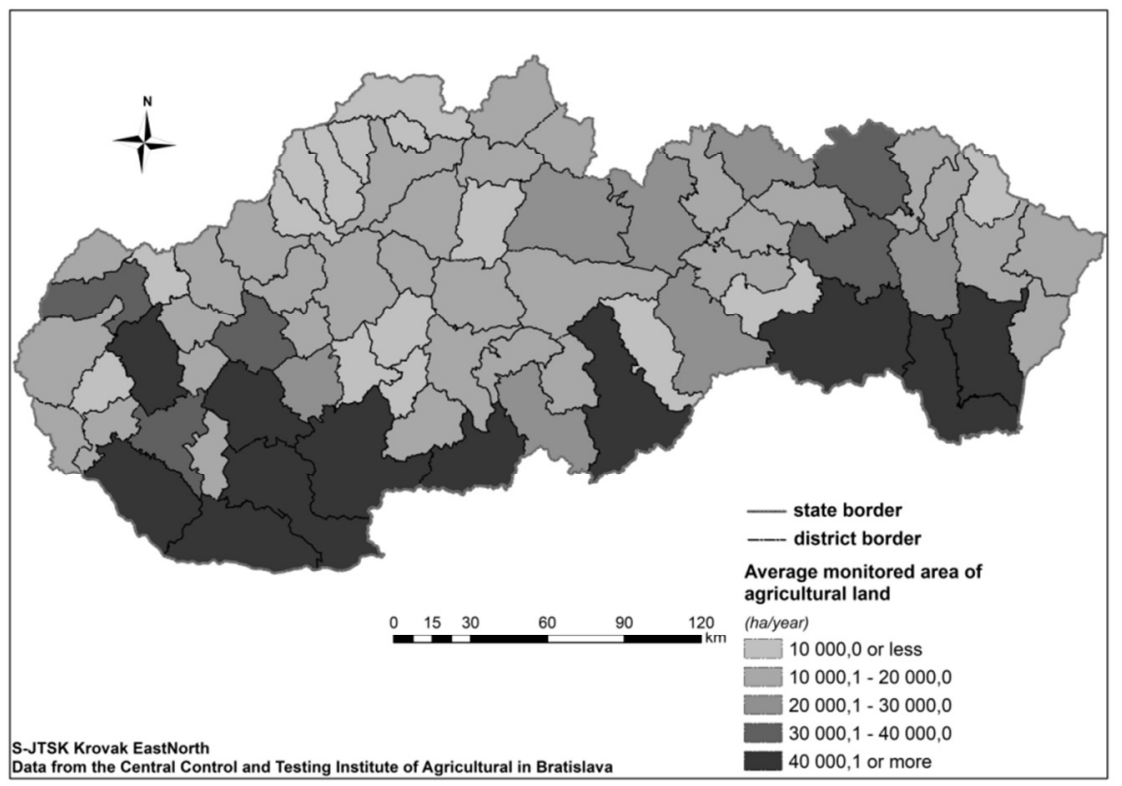


Figure 2. Development in average annual monitored area of agricultural land in the districts of Slovakia in the period 2006-2015

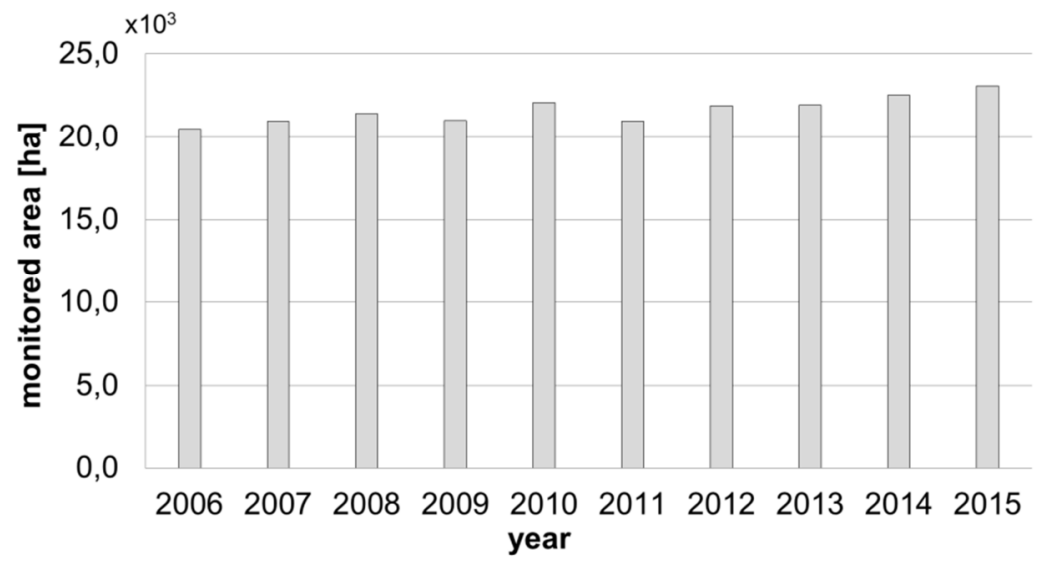

The highest total, but as well as average consumption of industrial fertilizers, we observed mainly in districts at the southwest part of Slovakia (Figure 3-4).

Figure 3. Total consumption of industrial fertilizers (nitrogenous, phosphoric and potassium) on monitored area of agricultural land in particular districts of Slovakia in the period 2006-2015

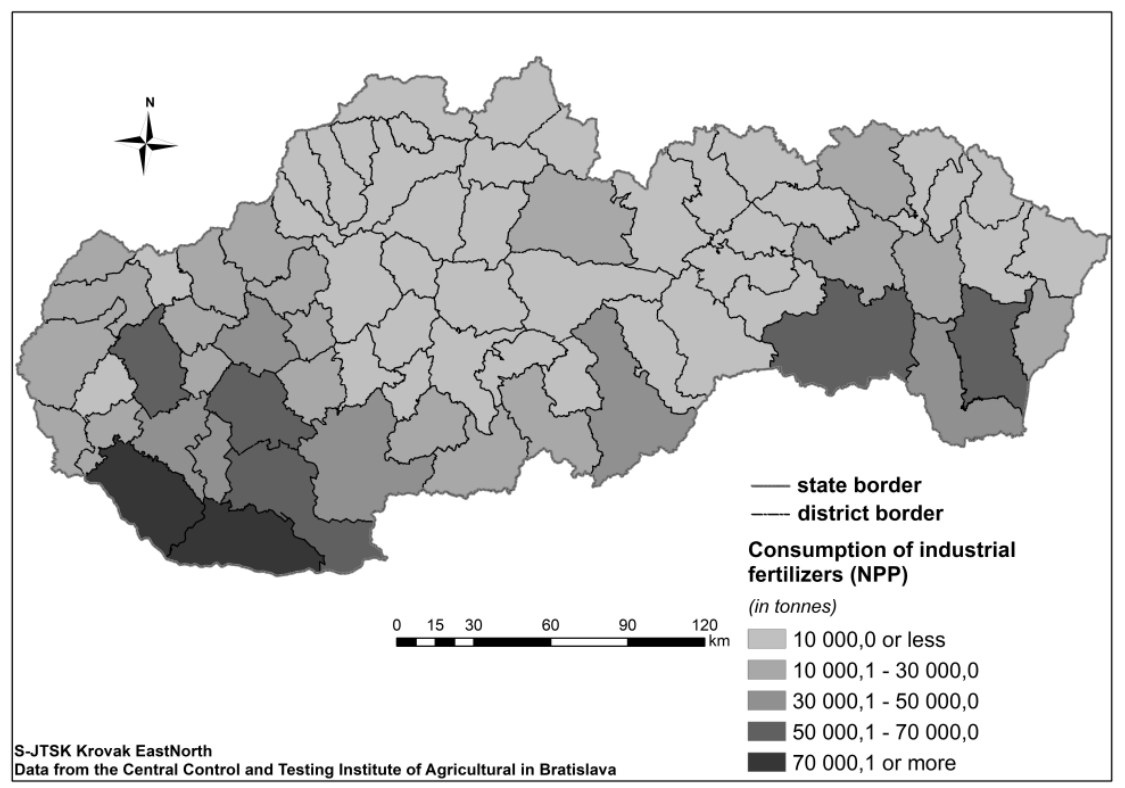


Figure 4. Average annual consumption of industrial fertilizers (nitrogenous, phosphoric and potassium) on 1 ha of monitored area of agricultural land in particular districts of

Slovakia in the period 2006-2015

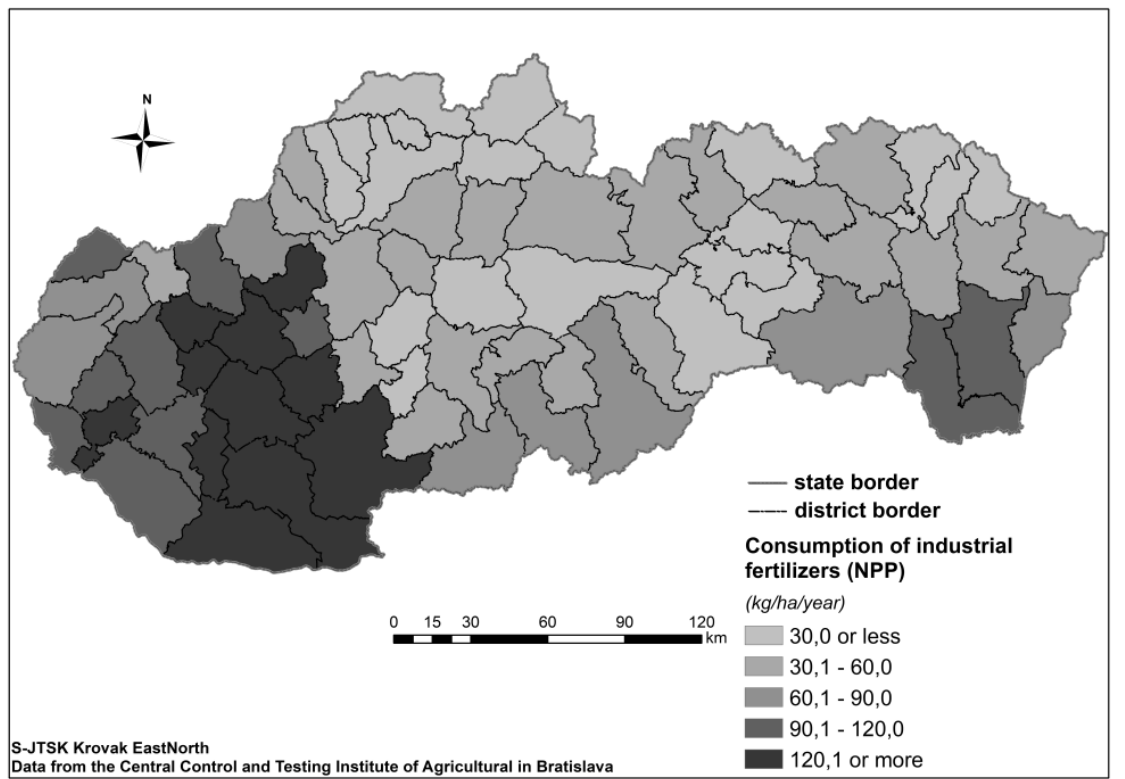

In the group of organic fertilizers, the highest values of total fertilizers consumption were in south half of Slovakia west part (Figure 5-6), although the amount of organic fertilizer consumption changed and fluctuated also in the particular district of this part of Slovakia (Figure 6). However, in average consumption of organic fertilizers the results were different and districts with higher average consumption of this type of fertilizers we identified not just in southwest part of Slovakia, but in the northern regions of Slovakia, for example Povazie, Liptov, and Orava (Figure 7). Mentioned discrepancy is connected mainly with animal production and by this way with production of organic fertilizers, as well as a smaller monitored area of agricultural land in these parts of Slovakia.

In monitored period, the annual amount of applied organic fertilizers was much higher than the annual amount of applied industrial fertilizers and in addition in a represented nitrogenous fertilizers (Figure 8). In the group of industrial fertilizers we observed two moderately increasing trends in their annual consumption during the period 2006-2015 (Figure 9) - one is in the period 2006-2008, the second one is in the period 20092015. On the other hand, in the group of organic fertilizers we observed one decreasing trend in consumption of these fertilizers in whole evaluated period (Figure 10). 
Figure 5. Total consumption of organic fertilizers on monitored area of agricultural land in particular districts of Slovakia in the period 2006-2015

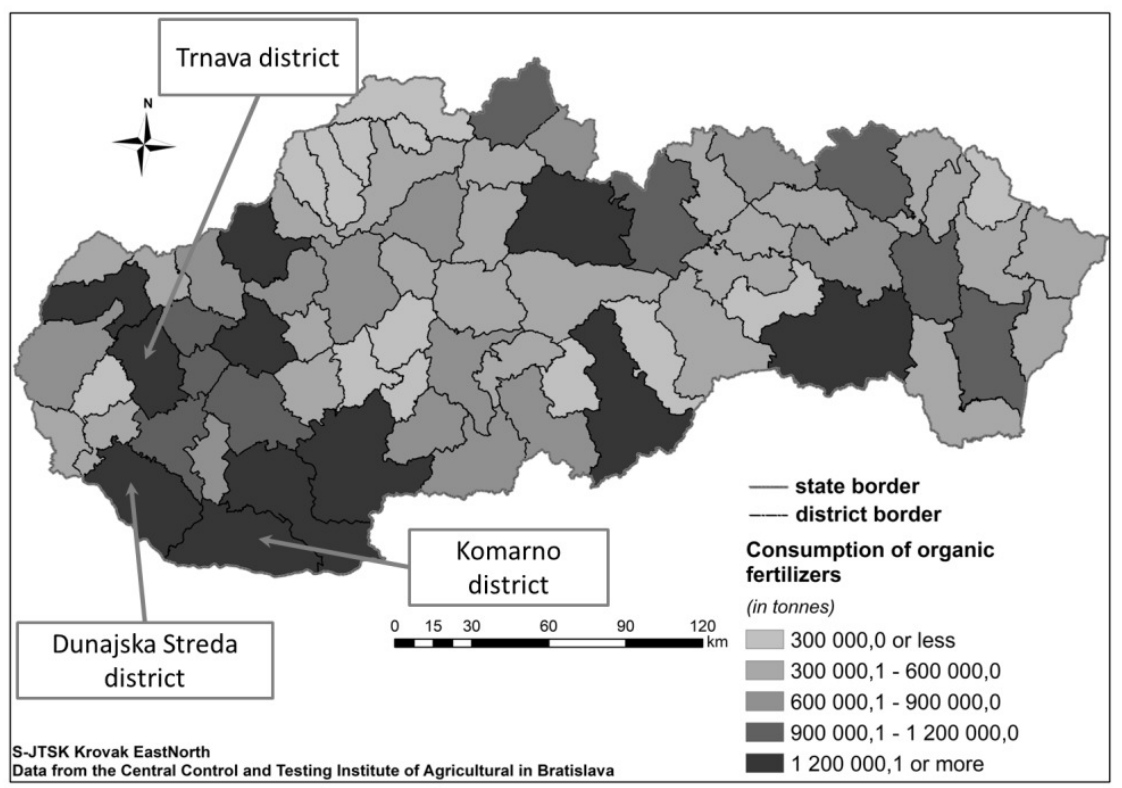

Figure 6. Trend of annual sum of organic fertilizers consumption on monitored area of agricultural land in Dunajska Streda, Trnava amd Komarno District during the period 2006-2015

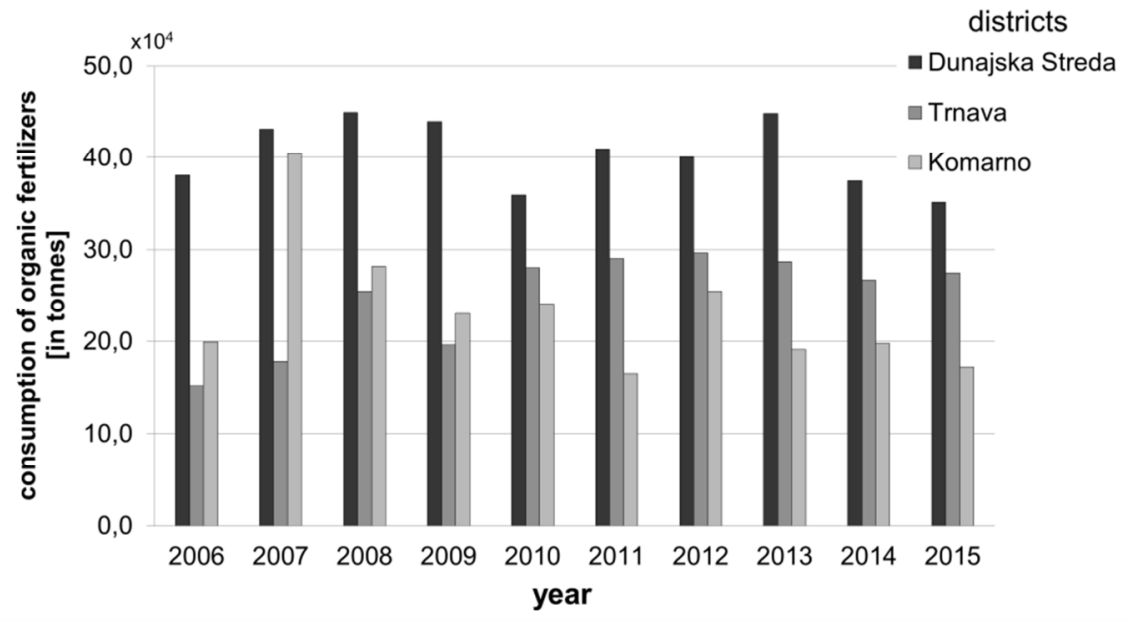


Figure 7. Average annual consumption of organic fertilizers on monitored area of agricultural land in particular districts of Slovakia in the period 2006-2015

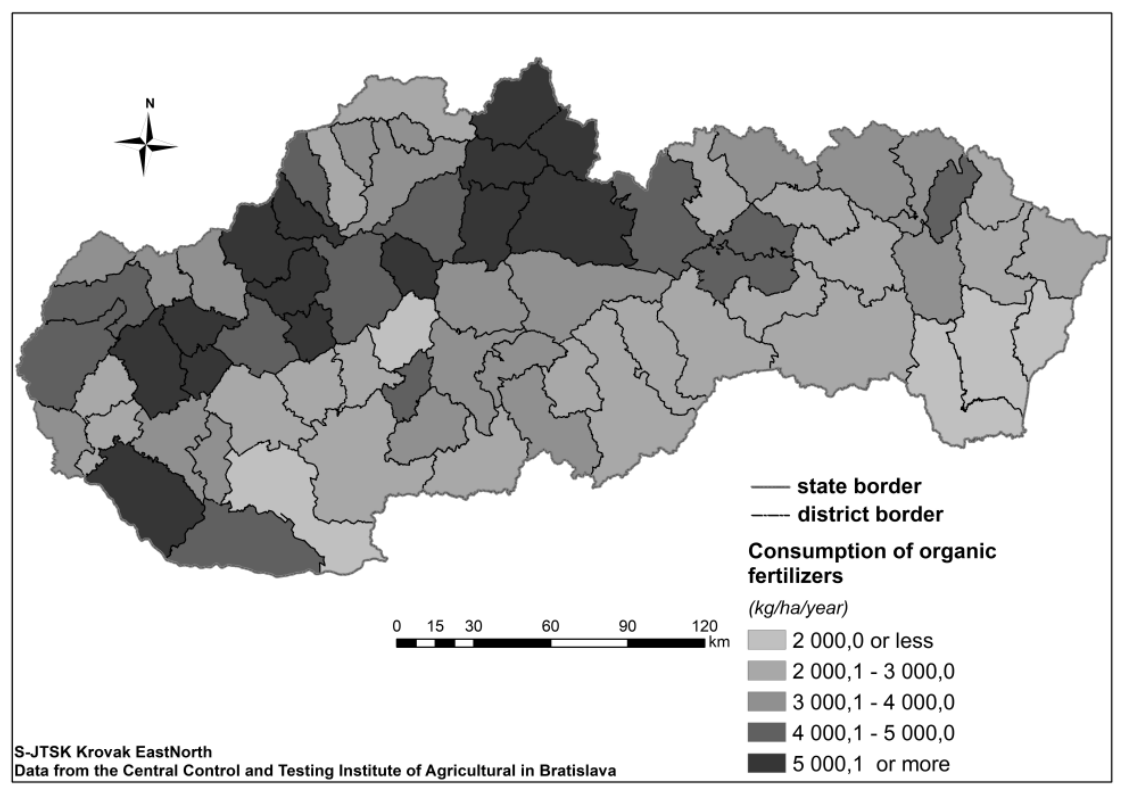

Figure 8. Trend of annual sum of industrial (nitrogenous, phosphoric and potassium separetely) and organic fertilizers on the whole monitored area of agricultural land of Slovakia in the period 2006-2015

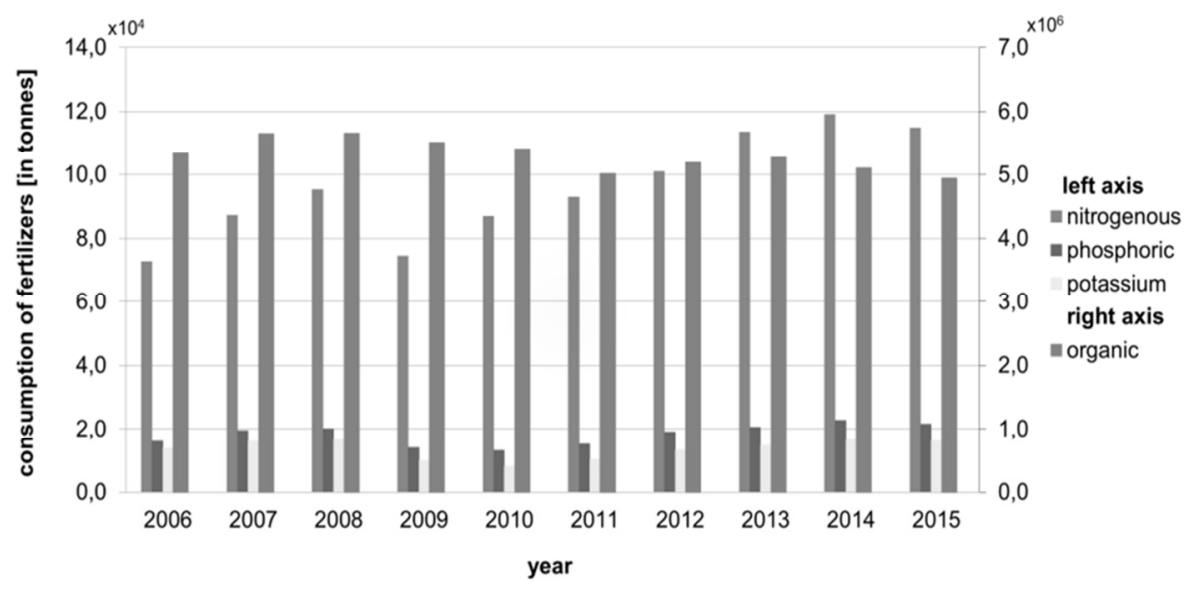


Figure 9. Trend of annual sum of industrial fertilizers (nitrogenous, phosphoric and potassium) consumption on the whole monitored area of agricultural land of Slovakia in the period 2006-2015

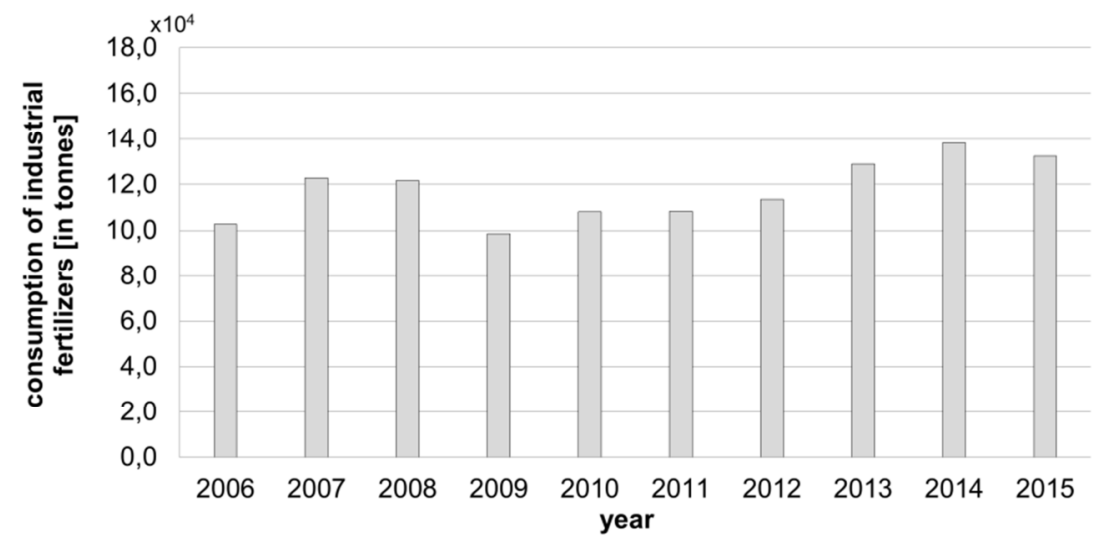

Figure 10. Trend of annual sum of organic fertilizers consumption on monitored area of agricultural land in districts of Slovakia in the period 2006-2015

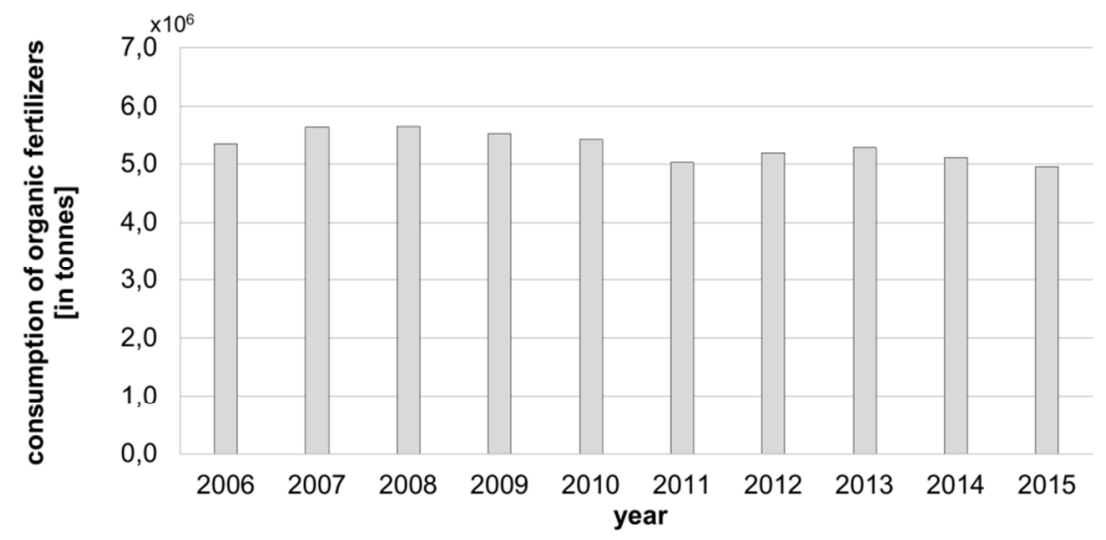

\section{Conclusion}

The objective of this paper was to identify areas with the potential highest and lowest level of non-point pollution of surface streams based on the processed data of organic and industrial fertilizers consumption in Slovakia during period 2006-2015. The highest average consumption of industrial fertilizers we observed mainly in districts in the southwest part of Slovakia, in a group of organic fertilizers, the districts with higher average consumption of this type of fertilizers was also identified in 
northern regions of Slovakia. In monitored period, the amount of applied organic fertilizers was much higher than the amount of applied industrial fertilizers (in a group of industrial fertilizers, a significant part of total fertilizers consumption had nitrogenous fertilizers). During the evaluated period there was identified two moderately increasing trends in industrial fertilizers annual consumption) - one is in the period 20062008, the second one is in the period 2009-2015. On the other hand, in the case of organic fertilizers there was observed one decreasing trend in consumption of these fertilizers in whole evaluated period. However, two gentle different trend was recognized in the same sub-periods gentle increasing in the period 2006-2008 and decreasing one in the period 2009-2015. Results of this analysis will be used for subsequent evaluation of potential risks to water resources quality at Slovakia territory.

\section{Acknowledgment}

The paper was created with support from VEGA project no. 1/0805/16. This contribution is the result of the project implementation ITMS 26220120062 Centre of excellence for the Integrated River Basin Management in the Changing Environmental Conditions, supported by the Research \& Development Operational Programme funded by the ERDF.

\section{References}

Amiri, B. J.-Nakane, K. (2009): Modeling the linkage between river water quality and landscape metrics in the Chugoku district of Japan. Water Resour. Manag. 23: 931-956.

Behrendt, H.-Huber, P.-Opity, D.-Scholy, G.-Uebe, R. (1999): Nährstof fbilanzierung der Flussgebiete Deutschlands 373 s. UBA-Bericht. Inst. f. Gewässerökologie und Binnenfischerei im Forschungsverbund Berlin e. V. Berlin.

Boskidis, I.-Gikas, G. D.-Pisinaras, V.-Tsihrintzis, V. A. (2011): Spatial and temporal changes of water quality, and SWAT modeling of Vosvozis River Basin, North Greece. J. Environ. Sci. Health. A45. 15: 421-1440.

Directive (2000): Directive 2000/60/EC of the European Parliament and of the council of 23 October 2000 establishing a framework for community action in the field of water policy. Official Journal of the European Communities. L327: $1-72$.

Donoso, G.-Cancino, J.-Magri, A. (1999): Effects of agricultural activities on water pollution with nitrates and pesticides in the central valley of Chile. Water Science and Technology. 39. 3: 49-60.

Duda, A. M. (1993): Addressing non-point sources of water pollution must become an international priority. Water Science and Technology. 28. 3-5: 1-11. 
Fischer, H. B.-List, J. E.-Koh, C. R.-Imberger, J.-Brooks, N. H. (1979): Mixing in Inland and Coastal Waters. Academic Press. New York. $483 \mathrm{~s}$.

Gikas, G. D.-Yiannakopoulou, T.-Tsihrintzis, V. A. (2006): Water quality trends in a coastal lagoon impacted by non-point source pollution after implementation of protective measures. Hydrobiologia. 563. 1: 385-406.

Humenik, F. J.-Smolen, M. D.-Dressing, S. A. (1987): Pollution form nonpoint sources: Where we are and where we should go. Environmental Science \& Technology. 21. 8: 737-742.

Kováčová, V. (2017): Nitrate dispersion-diffusion coefficients in agricultural soil profile of Žitný ostrov locality (Slovakia). Columella Journal of Agriculture and Environmental Sciences. 4. 1: 143-148.

Lam, Q. D.-Schmalz, B.-Fohrer, N. (2010): Modelling point and diffuse source pollution of nitrate in a rural lowland catchment using the SWAT model. Agr. Water Manage. 97: 317-325.

Lam, Q. D.-Schmalz, B.-Fohrer, N. (2011): The impact of agricultural Best Management Practices on water quality in a North German lowland catchment. Environ. Monit. Assess. 183. 1-4: 351-379.

Meybeck, M.-Chapman, D. V.-Helmer, R. (1989): Global Freshwater quality, a first assessment. WHO and UNEP/Blackwell Ltd.

Mouri, G.-Takizawa, S.-Oki, T. (2011): Spatial and temporal variation in nutrient parameters in stream water in a rural-urban catchment, Shikoku, Japan: Effects of land cover and human impact. Journal of Environmental Management. 92: 1837-1848.

Zalidis, G.-Stamatiadis, S.-Takavakoglou, V.-Eskridge, K.-Misopolinos, N. (2002): Impacts of agricultural practices on soil and water quality in the Mediterance region and proposed assessment methodology [online]. Agriculture, Ecosystems \& Environment. 88. 2: 133-146. https://www.sciencedirect. com/science/article/pii/S0167880901002493 (cit. 2018-06-28) 